\title{
Assessing the Probability of Drought Severity in a Homogeneous Region
}

\author{
Rizwan Niaz $\mathbb{D}^{1},{ }^{1}$ Mohammed M. A. Almazah ${ }^{(D)},{ }^{2,3}$ Ijaz Hussain $(\mathbb{D})^{1}$ \\ Joao Dehon Pontes Filho, ${ }^{4}$ Nadhir Al-Ansari $\mathbb{D}^{5},{ }^{5}$ and Saad Sh Sammen $\mathbb{D}^{6}$ \\ ${ }^{1}$ Department of Statistics, Quaid-i-Azam University, Islamabad, Pakistan \\ ${ }^{2}$ Department of Mathematics, College of Sciences and Arts (Muhyil), King Khalid University, Abha 61421, Saudi Arabia \\ ${ }^{3}$ Department of Mathematics and Computer, College of Sciences, Ibb University, Ibb 70270, Yemen \\ ${ }^{4}$ Hydraulic and Environmental Engineering Department (DEHA), Federal University of Ceará, Fortaleza, \\ Ceará 60020-181, Brazil \\ ${ }^{5}$ Department of Civil, Environmental and Natural Resources Engineering, Lulea University of Technology, Lulea 971 87, Sweden \\ ${ }^{6}$ Department of Civil Engineering, College of Engineering, University of Diyala, Diyala Governorate, Baqubah, Iraq
}

Correspondence should be addressed to Saad Sh Sammen; saad123engineer@yahoo.com

Received 16 October 2021; Revised 21 December 2021; Accepted 6 January 2022; Published 29 January 2022

Academic Editor: Qingyuan Zhu

Copyright (C) 2022 Rizwan Niaz et al. This is an open access article distributed under the Creative Commons Attribution License, which permits unrestricted use, distribution, and reproduction in any medium, provided the original work is properly cited.

The standardized precipitation index (SPI) is one of the most widely used indices for characterizing and monitoring drought in various regions. SPI's applicability has regional and time-scale constraints when it observes in several homogeneous climatic regions with similar characteristics. It also does not provide sufficient knowledge about precipitation deficits and the spatiotemporal evolution of drought. Therefore, a new method, the regional spatially agglomerative continuous drought probability monitoring system (RSACDPMS), is proposed to obtain spatiotemporal information and monitor drought characteristics more expeditiously. The proposed framework uses spatially agglomerative precipitation (SAP) and copulas' functions to continuously monitor the drought probability in the homogenous region. The RSACDPMS is validated in the region of the Northern area of Pakistan. The outcomes of the current study provide a better quantitative way to obtain appropriate information about precipitation deficits and the spatiotemporal evolution of drought.

\section{Introduction}

Drought is a creeping phenomenon that gradually spreads in an area over a period and may continue for a long period [1-4]. It is a multifaceted phenomenon that periodically fluctuates in many regions worldwide and becomes a cause of negative impacts $[5,6]$. Its impacts directly or indirectly affect humans' activities more than other natural hazards $[3,4,7,8]$. Furthermore, it negatively affects vast areas in several ways, such as distressing the region's economy, recreation, water resources, waterfowl, hydroelectric energy, forestry, and other environmental locations [9-11]. However, suitable drought monitoring measures can assist to reduce the negative impacts of drought in the affected area regarding the needs such as the region's economy, food, water resources, hydroelectric energy, and social security of the people. Although drought is primarily a water-associated hazard, it has been assessed and defined by several fields from various perspectives [12-14]. To bring some order to measure drought that substantially helps in investigating the various effects, the climatological scientists grouped the drought into four major types $[15,16]$. These definitions are associated with a shortage of precipitation over time [12-14].

The standardized procedures are commonly used for drought assessment and its characterization [17]. Numerous studies proposed several standardized drought indices for characterizing and monitoring drought $[18,20]$. The indices provide quantitative information about drought monitoring forecasting that helps decision makers with drought characteristics. Over the years, several drought indices have been 
developed for drought assessment. However, due to the complexity of the drought phenomena, several researchers proposed various drought indices to the specific climatic conditions. Some of the indices are used in specific regions and have some limitations of use under specific climatic conditions. For instance, Palmer [21] provided an index which is known as "Palmer drought severity index (PDSI)" and is extensively used in the United States. Gibbs and Maher [22] developed an index which is known as "Rainfall deciles as drought indicators (RDDIs) and functioning" in Australia. The China $Z$ index (CZI) was developed in China and is frequently used in China to identify and monitor drought events. However, among the various standardized indices, the standardized precipitation index (SPI), developed by McKee et al. [23], is frequently used. The SPI uses precipitation data to assess meteorological drought on various time scales. It prevails in developing drought monitoring and mitigating policies [24, 25]. Furthermore, the standardized values of the SPI, therefore, can be used to compare in different climatic zones $[13,19,26,27]$. The SPI has been frequently considered to identify or envisage drought events; however, standardized numerical values of the index become challenging when associated with the precipitation deficits and the temporal evolution of droughts $[28,29]$. Therefore, it is important to develop a new method that provides information about the precipitation deficits, drought probability, and temporal evolution of the droughts.

Usually, drought occurrences are identified by the univariate setting. However, the climatological characteristics of hydrological phenomena consist of the dependence structure. The univariate setting could not be able to consider the dependence structure. Since univariate approaches cannot perform well and become insufficient in hydrological phenomena [30]. Therefore, multivariate techniques were developed to address the dependence structure of the characteristics to enhance the efficiency of the estimates in hydrological studies. These techniques have several shortcomings; for example, these techniques do not explicitly model more than two variables. These techniques are also based on the condition that marginal must have a similar probability distribution that restricts them from illustrating other individual dependence structures. The research is therefore needed to develop techniques that explicitly describe the dependence structure to overcome these issues. In this regard, the concept of copula-based modeling was introduced that has some flexibility. For instance, copula-based modeling extensively assesses a multivariate dependence structure and joint distributions through mainly categorizing the dependence structure of random variables from their marginal distributions [31]. The copulas and their applications in drought have achieved significant importance for joint modeling of drought indices [32]. Furthermore, copulas' functions were used to evaluate varying characteristics of the drought events (e.g., duration, magnitude, intensity, and spatial distribution). In climatic regions such as the Northern area of Pakistan, the major source of drought events is insufficient precipitation during the rainy season. An advanced copula-based methodology is employed to observe the advancement in drought probability by using continuous precipitation information.

The present study proposes the Regional Spatially Agglomerative Continuous Drought Probability Monitoring System (RSACDPMS) to calculate more accurate and comprehensive information about homogeneous stations and monitor regional drought characteristics more expeditiously. The RSACDPMS utilizes spatially agglomerative precipitation (SAP) and copulas' functions to continuously monitor the drought probability in the homogeneous region. The proposed framework is validated on six meteorological stations in the Northern area of Pakistan. The study provides a better quantitative way of analyzing drought at the regional level.

\section{Methods}

2.1. Copula's Theory. The predictive relationship between two or more than two variables can be analyzed by studying their dependence structure. Mostly, the relationship among the variables can be analyzed using the Pearson correlation coefficient. However, this method cannot consider structural dependence but the degree of dependence. Furthermore, the structural dependence remains unimportant by using this method. Therefore, the nonlinear dependence structure between the variables can be judged by the rank correlation coefficient. Generally, this nonlinear dependence structure is assessed by using Spearman rank correlation and Kendall's Tau. Moreover, the use of Kendall's Tau is frequent because it helps to determine the concordant or discordant pairs' probability directly. The relationship between the correlation coefficient and copula function allows assessing the liner dependencies [33]. For this purpose, Sklar's theorem has gained substantial importance on the various characteristics for the analysis in literature [33,34]. For instance, random variables, we can say $y_{1}, \ldots, y_{d}$ which are following a marginal probability distribution function $F_{1}\left(y_{1}\right), \ldots, F_{d}\left(y_{d}\right)$, respectively, there exists a copula, C [35], that can be used to join these functions of marginal distribution in the form of a joint distribution function, as shown in the following equation:

$$
\begin{aligned}
H\left(y_{1}, y_{2}, y_{3} \ldots, y_{d}\right) & =\left(F_{1}\left(y_{1}\right), F_{2}\left(y_{2}\right), F_{3}\left(y_{3}\right), F_{d}\left(y_{d}, F_{d}\left(y_{d}\right)\right)\right) \\
& =C\left(u_{1}, u_{2}, u_{3} \ldots, u_{d}\right)
\end{aligned}
$$


where $F_{k}\left(y_{k}\right)=u_{k}$ for $k=1,2,3, \ldots \ldots, m$, with $u_{k} \sim u(0,1)$, and $C\left(u_{1}, u_{2}, \ldots, u_{d}\right)$ is envisioned as the copula function. The copulas have been employed as a convenient and useful method in distinct parts of several fields [33, 35]. These various characteristics can be predicted by helping multivariate copulas.

\subsection{Regional Spatially Agglomerative Continuous Drought} Probability Monitoring (RSACDPMS). The RSACDPMS uses regional-level characteristics to continuously monitor the drought probability in the Northern area of Pakistan. The RSACDPMS provides knowledge for several homogeneous climatic regions and monitors drought characteristics more expeditiously. To complete this work, the following steps are described accordingly.

\subsubsection{Seasonal Threshold at the Regional Level Definition.} The major concern of the study is to monitor advances regarding precipitation at the regional level. For this purpose, the present study proposed RSACDPMS that calculates the regional thresholds. This calculation is based on the following steps. The precipitation thresholds for four drought severity conditions ("extremely dry, severely dry, median dry, and normal dry") are calculated. These severity conditions are defined in the literature and are classified according to literature [36]. The RSACDPMS can be used for other drought severity conditions accordingly. However, the present study considers them according to current requirements for the research. The rainy season of six months (January to June) is selected for the current analysis. During this selected season, most of the rain falls for this region [37, 38]. The selected rainy season is important for the climatological characteristics. This season accounts for $70 \%$ to $80 \%$ of the annual rainfall from January to June. The dependency of the other parts of the country is highly linked to this rainy period. The rainy season provides high precipitation, which substantially contributes to the major river system (Indus) in Pakistan. For the rainy period of six months, the SPI is used to drought-triggering precipitation thresholds. Furthermore, the data of the selected stations present a homogeneous environment. Niaz et al. [39] proposed a framework to accumulate information from homogeneous stations. The mentioned study selected the standardized values of the drought category from the varying stations. However, the present study uses the same methodology for selecting precipitation data of the homogeneous stations, which is called "spatially agglomerative precipitation (SAP)."

2.2.2. Converting SPI for the Period. The SPI, which was firstly introduced by McKee et al. [23], has frequently been considered for assessing and characterizing the meteorological drought. The SPI can quantify the standardized discrepancy from selected probability distributions that model the raw data to observe precipitation $[19,26]$. Furthermore, SPI reliability found significant distribution in different climatic scenarios (geographical and temporal distribution) and makes it more recognized worldwide $[19,40]$. However, the SPI index is insufficient to monitor continuing drought characteristics because it cannot provide expeditious information associated with precipitation deficits, drought probability, and the temporal evaluation of droughts $[28,29])$. Furthermore, the deficiency in the precipitation causes the main factor of the drought occurrences. Therefore, the RSACDPMS based on copulas and steady-state probabilities is developed to give the regional level probability of having drought as the rainy season advances by assigning the SPI- 6 to drought-triggering precipitation thresholds. The purpose of the proposed RSACDPMS is related to the precipitation advances in the region.

2.2.3. Copula's Fitting. The time series of precipitation data is used for the characterization of the drought. The rainy season of the time-series data is used to envisage the drought occurrences in the selected stations. The thresholds concept proposed by Santos et al. [28] and used by Pontes Filho et al. [29] is also used for the analysis with adaptation. The mentioned studies calculate the precipitation thresholds corresponding to each drought intensity using the generic probabilities proposed by Agnew [41]. However, in the current study, the probabilities for each drought severity condition are obtained by the steady-state probabilities, specifically for the application site. Moreover, the significant difference is that the RSACDPMS was initiated to continuously monitor the drought probability over the Northern area of Pakistan. The precipitation threshold is a significant concern of the analysis. The precipitation thresholds for a region and drought severity are calculated by converting the SPI from January to June, SPI- 6 . In the studied region, the selected season (January to June) accounts for $70 \%$ to $80 \%$ of the annual rainfall. The current study is performed to obtain accurate information and timely inform the meteorologists and policymakers to understand the growing risk of drought. For this perspective, the present analysis is accomplished by considering the copula-based method. Numerous studies discuss the families of the copulas in literature [35]. Moreover, the copulas were grouped into four prominent families: extreme value type, meta-elliptical copulas, and Archimedean copulas. Because archimedean copulas have accessible properties in hydrological analyses, it is therefore very prevalent in modeling dependence structures, especially in measuring the dependent tail structures [42]. The Archimedean copulas have limitations for modeling higher-order dependency structures between/among variables. Meta-elliptical copulas [43] can be used to assess such higher-order types in the dependent structure. Furthermore, Archimedean copulas (Gumbel) and meta-elliptical copulas (Gaussian and Student $t$ ) were selected as candidates given in the following equations-:

$$
\begin{aligned}
& \text { Gumbel exp }\left\{-\left[\left(-\ln u_{1}\right)^{\varnothing}+\left(-\ln u_{1}\right)^{\varnothing}\right]^{\frac{1}{\varnothing}},\right. \\
& \text { Gaussian } \theta_{\rho}\left(\theta^{-1}\left(u_{1}\right)\right)+\theta^{-1}\left(u_{2}\right),
\end{aligned}
$$




$$
\mathrm{t}-\text { Student } T_{\rho, v}\left(T_{v}{ }^{-1}\left(u_{1}\right)\right),\left(T_{v}{ }^{-1}\left(u_{2}\right)\right) .
$$

\section{Application}

The suitable selection of the region (see Figure 1) for the analysis can improve the capabilities for drought assessment. The selected region has important features regarding the climatological characteristics, including the dependency of the other regions of the country and high altitude, which significantly influences the different parts; it holds a large water frozen reservoir, which substantially contributes to the major river system (Indus) in Pakistan. Therefore, the study selects the most suitable region for the analysis region and develops a widespread basis of permeating evaporative and considerable effect for the irrigation of agriculture sectors of the country [44-46]. The agriculture sectors play a significant role in the development of the country [47-50]). Recently, the agriculture sectors of the country were affected by global warming [51]. Global warming affects widespread places of the world; its impacts are stirring Pakistan's water temperature scarcity. Generally, the drought existences have damaged the economic sector, farming, and agriculture sectors. Particularly, the drought has severely damaged human life and the agriculture sector for the last three decades in Sindh (Province of Pakistan). Therefore, the country needs a comprehensive and substantial method to monitor drought characteristics more quickly by developing inclusive and trustful tools. However, the current outcomes are determined to improve the ability of drought monitoring and mitigation policies significantly.

3.1. Results. The deficiency of precipitation and disturbance to an expected precipitation pattern becomes the main forcing factor for a drought. The drought produces adverse consequences on society and the economy. Therefore, the researchers developed various methods and procedures to reduce the potential negative impacts of drought. However, there are very few studies that focus on drought monitoring in homogeneous regions $[39,52,53]$. The current study used monthly precipitation data to classify the different drought severities in a homogeneous region. The various drought severity conditions are classified according to literature [36]. The steady-state probabilities are used to calculate precipitation thresholds to monitor drought probability and temporal evaluation (Table 1). The steady-state probability is defined as the probability of drought severity in the long run duration. The calculated precipitation thresholds, $R_{N}^{*}$ for the rainy season of six months, January to June, at varying drought severities for a region are given in Table 2. The Brier skill score (BSS) values are used to profess the performance of the RSACDPMS. The mathematical description of BSS is available in $[29,39]$. In Table 3 , the BSS values for normal droughts are given. A value close to 1 represents that model performance is better. Furthermore, $n$ rises the predicting performance of the RSACDPMS rises as well. The average value of all the stations for $n=1$ is 0.30 , while it increases to 0.32 for $n=2$ and increases to 0.87 for $n=5$. Furthermore, the probability distributions frequently used for the standardization of SPI, steady-state probabilities, and copula functions (to evaluate the dependence structure of a rainy season's precipitation and its subperiod precipitation) are used in RSACDPMS to calculate the precipitation thresholds in the selected region.

This study tested the most popular Archimedean copulas (Clayton, Gumbel, and Frank) and meta-elliptical copulas (Gaussian and Student $t$ ). These copulas' families have been defined in literature $[35,42]$. The candidate copulas families are selected based on the Akaike information criterion (AIC). The parameters' estimation of the selected families of the copulas is carried out by the maximum pseudolikelihood (MPL). Furthermore, the bivariate models are used for selecting each subperiod $(n)$, for January $(n=1)$ and May $(n=5)$ (Table 4). The progressive records of the precipitation are observed by Kendall's Tau correlation coefficient (KTCC). KTCC witnesses that the precipitation integrated progressively in the model. The stronger structure of the dependencies $R_{N}$ and $R_{n}$ is observed which means that the $30 \%$ precipitation of the rainy season is explained by $n_{1}$, while $n_{5}$ explains $90 \%$ of rainfall. The slight disparity between the model and the empirical Kendall's Tau estimates infers that $R_{N}$ and $R_{n}$ are suitably modeled by using copulas. The small $p$-values provide considerable indication against the independence of the structure. When bivariate models are fitted, the next step is to monitor drought probability in chosen stations for every month.

The year 2017 is being selected as an example to continuously show the capabilities of RSACDPMS to monitor drought for that year (Table 5). In January, the observed precipitation is $16 \mathrm{~mm}$, and the climatological precipitation for this month is $22.78 \mathrm{~mm}$. Thus, RSACDPMS has already started to show the risk of a drought in the first semester given the rain in the first month. To occur a normal dry, its probability is 0.72 , as the first value is already below the mean. However, it is not so low, and the other drought categories do not present high probabilities as well, and 0.39, 0.34 , and 0.009 are for median, severe, and extremely dry conditions. February comes with another month's below mean values, and the two-month accumulated precipitation, which is 34.2 , already shows a deficit of $17.9 \mathrm{~mm}$ from the climatological accumulated mean of $52.13 \mathrm{~mm}$. This situation kept the normal dry probabilities high but is enough to significantly decrease the other categories' probabilities as they got closer to their precipitation thresholds. In March, the drought severity level (i.e., extremely dry (ED)) is already out of option as the precipitation accumulated by this month, $60.9 \mathrm{~mm}$, is already higher than the ED threshold of 55.29. By April, the observed accumulated precipitation is already greater than all drought severities but one, the closest to normal condition. When June is ended and with it, the rainy season, the accumulated precipitation for 2017 is $102.8 \mathrm{~mm}$, which is below the climatological mean $(134.42 \mathrm{~mm})$. Moreover, the mean of the accumulated precipitation $(102.8 \mathrm{~mm})$ is not enough to meet the normal dry (ND) threshold $(120.99 \mathrm{~mm})$. Therefore, RSACDPMS permitted decision makers to understand the growing risk of drought in that year and what category it would represent. 


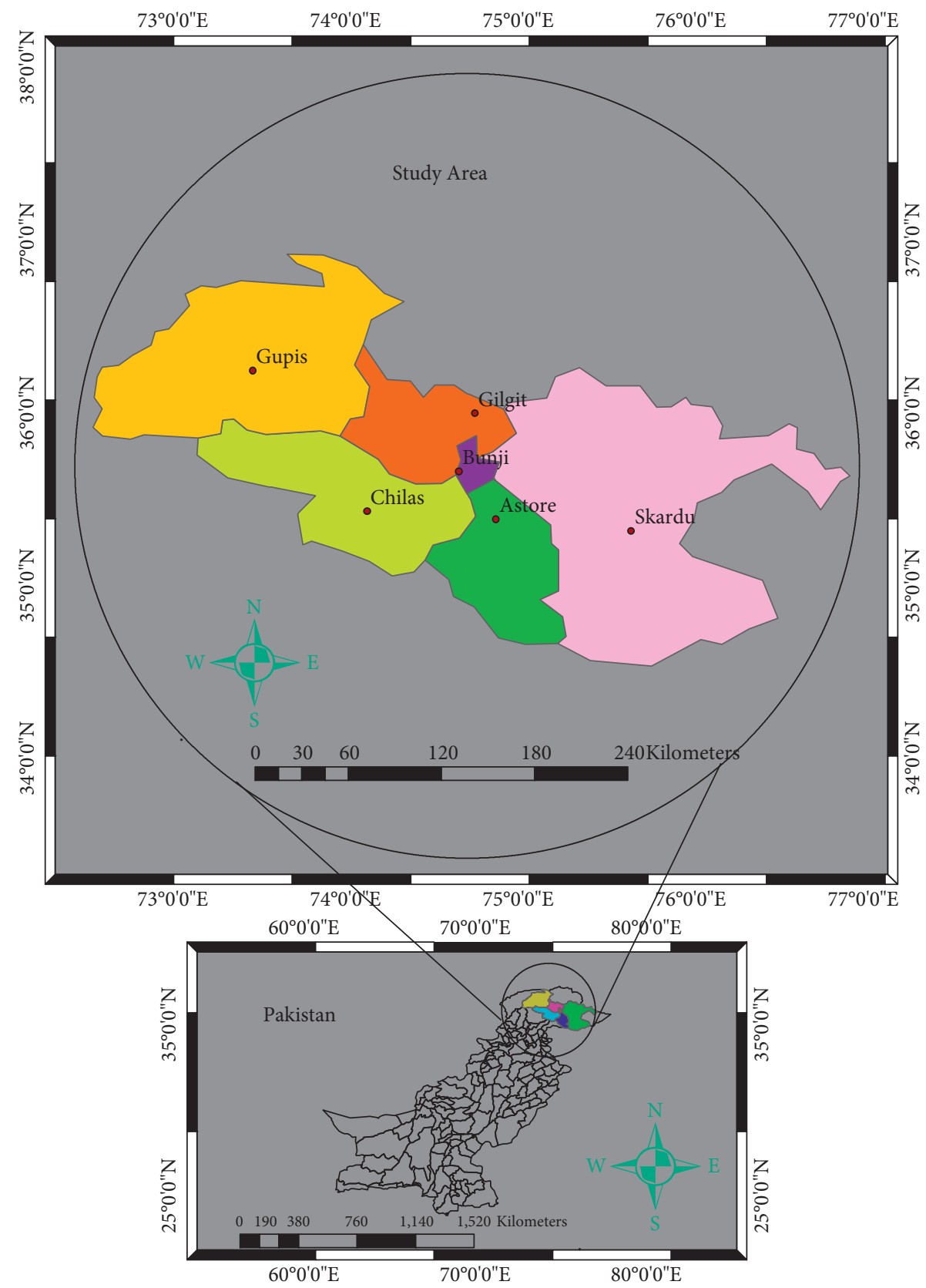

Selected Stations
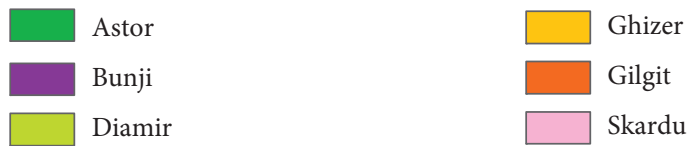

Figure 1: Geographical locations of the six selected stations of the Northern area of Pakistan.

For example, in March, the ND condition has 0.78 drought risk while other categories have much less drought risk. Therefore, anticipated measures that fit the exact proportions of normal drought could be implemented to mitigate its potential negative outcomes.
3.2. Discussion. The present study develops a new method to timely inform the meteorologists and policymakers to understand the growing risk of drought. For this purpose, Pontes Filho et al. [29] proposed the continuous drought probability monitoring system (CDPMS) to monitor drought occurrences 
TABLE 1: The steady-state probabilities observed for various drought conditions.

\begin{tabular}{lcccc}
\hline SPI & SPI $>-1 \&$ SPI $\leq 1$ & SPI $>-1.5 \&$ SPI $\leq-1$ & SPI $>-2$ \& SPI $\leq-1.5$ & SPI $\leq-2$ \\
\hline Drought classes & Normal dry & Median dry & Severely dry & Extremely dry \\
Steady state probabilities & 0.53 & 0.17 & 0.14 & 0.05 \\
\hline
\end{tabular}

TAвLE 2: The precipitation thresholds for various drought conditions (extremely dry, severely dry, median dry, and normal dry) are provided.

\begin{tabular}{lcccc}
\hline Drought intensity & Extremely dry & Severely dry & Median dry & Normal dry \\
\hline Precipitation thresholds $(\mathrm{mm})$ & 55.29 & 66.05 & 70.04 & 120.99 \\
\hline
\end{tabular}

TABLE 3: BSS values $n=1$ to $n=5$ for the normal droughts.

\begin{tabular}{lcccccc}
\hline Region & $n=1$ & $n=2$ & $n=3$ & $n=4$ & $n=5$ & Average \\
\hline Northern area & 0.30 & 0.32 & 0.39 & 0.71 & 0.87 & 0.65 \\
\hline
\end{tabular}

TABLE 4: Each coupled $\left(R_{N}, R_{n}\right)$ series for bivariate models, their parameters, Kendall's Tau correlation (according to the model and empirical), AIC, and $\mathrm{p}$ values at the Northern area.

\begin{tabular}{|c|c|c|c|c|c|c|c|}
\hline \multirow[b]{2}{*}{$R_{n}$} & \multirow[b]{2}{*}{ Family } & \multicolumn{2}{|c|}{ Parameters } & \multicolumn{2}{|c|}{ Kendall's tau } & \multirow[b]{2}{*}{ AIC } & \multirow[b]{2}{*}{$p$ value } \\
\hline & & $\varnothing$ or $\rho$ & $v$ & Model & Empirical & & \\
\hline$n_{1}$ & Gumbel & 1.50 & - & 0.33 & 0.30 & -10.49 & $<0.05$ \\
\hline$n_{2}$ & Gumbel & 1.98 & - & 0.49 & 0.45 & -27.98 & $<0.05$ \\
\hline$n_{3}$ & $T$ & 0.74 & 2.0 & 0.53 & 0.54 & -40.71 & $<0.05$ \\
\hline$n_{4}$ & Gaussian & 0.91 & - & 0.74 & 0.72 & -81.71 & $<0.05$ \\
\hline$n_{5}$ & Gumbel & 10.23 & - & 0.90 & 0.91 & -162.6 & $<0.05$ \\
\hline
\end{tabular}

TABle 5: Probability of extreme, severe, median, and normal drought events along the rainy season of 2017 (January to June) at scale 6 according to the RSACDPMS framework for the Northern area.

\begin{tabular}{|c|c|c|c|c|c|c|c|}
\hline & & January & February & March & April & May & June \\
\hline \multirow{2}{*}{ Mean monthly precipitation ( $\mathrm{mm})$} & Monthly & 22.78 & 29.35 & 22.41 & 27.55 & 20.28 & 12.05 \\
\hline & Accumulated & 22.78 & 52.13 & 74.54 & 102.09 & 122.37 & 134.42 \\
\hline \multirow{2}{*}{ Observed precipitation $(\mathrm{mm})$} & Monthly & 16 & 18.2 & 26.7 & 15.2 & 16.1 & 10.6 \\
\hline & Accumulated & 16 & 34.2 & 60.9 & 76.1 & 92.2 & 102.8 \\
\hline \multicolumn{2}{|c|}{ Drought category (threshold) } & \multicolumn{6}{|c|}{ Drought risk } \\
\hline \multicolumn{2}{|c|}{ Extremely dry (55.29) } & 0.09 & 0.07 & 0.00 & 0.00 & 0.00 & No drought \\
\hline \multicolumn{2}{|l|}{ Severely dry (66.04) } & 0.34 & 0.03 & 0.01 & 0.00 & 0.00 & No drought \\
\hline \multicolumn{2}{|l|}{ Median dry (70.05) } & 0.39 & 0.04 & 0.02 & 0.00 & 0.00 & No drought \\
\hline \multicolumn{2}{|l|}{ Normal dry (120.90) } & 0.72 & 0.59 & 0.78 & 0.94 & 0.96 & Drought \\
\hline
\end{tabular}

and translate their probability of occurrence into user-friendly information mathematical transformations. It was applied at the rain gauge level in Portugal, but droughts are usually widespread in large areas. The mentioned study used generic probabilities proposed by Agnew [41] and Gamma distribution to calculate precipitation thresholds in their study. Furthermore, Niaz et al. [39] proposed modified CDPMS to monitor drought occurrences in Punjab and Pakistan. The study used various probability distributions (instead of Gamma distribution), copulas, and steady-state probabilities (instead of generic probabilities) to translate the probability of drought occurrence into user-friendly information mathematical transformations. However, the present study proposes the RSACDPMS to calculate more accurate and comprehensive information about the homogeneous regions and monitor regional drought characteristics more expeditiously. The inclusion of regional spatiotemporal information makes this study innovative. RSACDPMS may receive more importance than CDMPS [29] and MCDPMS [39] at the regional level, specifically, in the homogeneous region. Now, the modification in CDMPS and MCDPMS allows users to calculate precipitation thresholds for the homogeneous region. This modification increases the accuracy and efficiency to determine thresholds for the drought severity.

\section{Conclusion}

In this study, the dependency between precipitation of the season's total and the observed precipitation at individual months is addressed by using bivariate copula-based models. 
The selection of the classes of the copulas families is based on the AIC criterion. The MPL method is employed for estimating the parameters of the copula's families. Furthermore, to continuously monitor the drought probability over the Northern area and monitor advances regarding precipitation at the regional level, the current study proposes RSACDPMS that provides information about the regional advances including the precipitation deficits, drought probability, and spatiotemporal evolution of the drought. The RSACDPMS is validated in the Northern area of Pakistan. Consequently, RSACDPMS enables decision makers to identify the increasing risk of drought severity in the homogeneous region. Furthermore, the RSACDPMS provides information to execute the exact proportions of such a drought's anticipated measures to decrease the possible negative effects of the specific drought condition. For example, in March 2017, the ND condition appears with drought risk (0.78), while other classes have much less drought risk. Therefore, anticipated measures that fit the exact proportions of ND could be implemented to decrease its potential negative effects. The outcomes obtained from the RSACDPMS may improve the monitoring abilities in rainy season advances of the selected region.

\section{Data Availability}

The data used for the preparation of the manuscript are available with the corresponding author and can be provided upon request.

\section{Ethical Approval}

All procedures followed were under the ethical standards of the responsible committee on human experimentation (institutional and national) and with the Helsinki Declaration of 1975, as revised in 2000 .

\section{Consent}

All authors voluntarily agreed to participate in this research study. All authors agreed for publication, and there is no legal constraint in publishing the data used in the manuscript.

\section{Conflicts of Interest}

The authors declare that there are no conflicts of interest.

\section{Acknowledgments}

The authors extend their appreciation to the Deanship of Scientific Research at King Khalid University for funding this work under grant number (RGP.2/4/43), received by Mohammed M. Almazah (http://www.kku.edu.sa).

\section{References}

[1] A. C. Chipanshi, K. M. Findlater, T. Hadwen, and E. G. O'Brien, "Analysis of consecutive droughts on the Canadian Prairies," Climate Research, vol. 30, no. 3, pp. 175-187, 2006.
[2] J. Maybank, B. Bonsai, K. Jones et al., "Drought as a natural disaster," Atmosphere-Ocean, vol. 33, no. 2, pp. 195-222, 1995.

[3] L. Zhang, W. Jiao, H. Zhang, C. Huang, and Q. Tong, "Studying drought phenomena in the Continental United States in 2011 and 2012 using various drought indices," Remote Sensing of Environment, vol. 190, pp. 96-106, 2017.

[4] R. Staupe-Delgado, "Progress, traditions and future directions in research on disasters involving slow-onset hazards," $D i$ saster Prevention and Management: International Journal, vol. 28, 2019.

[5] R. Stephan, M. Erfurt, S. Terzi et al., "An inventory of Alpine drought impact reports to explore past droughts in a mountain region," Natural Hazards and Earth System Sciences, vol. 21, no. 8, pp. 2485-2501, 2021.

[6] Y. Liu, R. Zhou, Z. Wen et al., "Assessing the impacts of drought on net primary productivity of global land biomes in different climate zones," Ecological Indicators, vol. 130, Article ID 108146, 2021.

[7] M. Savari and M. Shokati Amghani, "Factors influencing farmers' adaptation strategies in confronting the drought in Iran," Environment, Development and Sustainability, vol. 23, pp. 4949-4972, 2021.

[8] O. Rojas, "Next generation agricultural stress index system (ASIS) for agricultural drought monitoring," Remote Sensing, vol. 13 , no. 5, 2021.

[9] G. Salmoral, B. Ababio, and I. P. Holman, "Drought impacts, coping responses and adaptation in the UK outdoor livestock sector: insights to increase drought resilience," Land, vol. 9, no. $6,2020$.

[10] V. Iese, A. S. Kiem, A. Mariner et al., "Historical and future drought impacts in the Pacific islands and atolls," Climatic Change, vol. 166, no. 1, pp. 1-24, 2021.

[11] A. Fu, W. Li, Y. Chen et al., "The effects of ecological rehabilitation projects on the resilience of an extremely droughtprone desert riparian forest ecosystem in the Tarim River Basin, Xinjiang, China," Scientific Reports, vol. 11, no. 1, pp. 1-11, 2021.

[12] A. Abdelraheem, N. Esmaeili, M. O'Connell, and J. Zhang, "Progress and perspective on drought and salt stress tolerance in cotton," Industrial Crops and Products, vol. 130, pp. 118129, 2019.

[13] M. Fooladi, M. H. Golmohammadi, H. R. Safavi, and V. P. Singh, "Application of meteorological drought for assessing watershed health using fuzzy-based reliability, resilience, and vulnerability," International Journal of Disaster Risk Reduction, vol. 66, Article ID 102616, 2021.

[14] T. Caloiero and S. Veltri, "Drought assessment in the sardinia region (Italy) during 1922-2011 using the standardized precipitation index," Pure and Applied Geophysics, vol. 176, no. 2, pp. 925-935, 2019.

[15] J. Zhao, Q. Zhang, X. Zhu, Z. Shen, and H. Yu, "Drought risk assessment in China: evaluation framework and influencing factors," Geography and Sustainability, vol. 1, no. 3, pp. 220-228, 2020.

[16] A. Y. Kassaye, G. Shao, X. Wang, and S. Wu, "Quantification of Drought Severity Change in Ethiopia during 1952-2017," Environment, Development and Sustainability, vol. 23, no. 11, pp. 1-26, 2020.

[17] K. Alsafadi, S. A. Mohammed, B. Ayugi, M. Sharaf, and E. Harsányi, "Spatial-temporal evolution of drought characteristics over Hungary between 1961 and 2010," Pure and Applied Geophysics, vol. 177, pp. 1-18, 2020.

[18] T. M. Erhardt and C. Czado, "Standardized drought indices: a novel univariate and multivariate approach," Journal of the 
Royal Statistical Society: Series C (Applied Statistics), vol. 67, no. 3, pp. 643-664, 2018.

[19] D. H. Mlenga, A. J. Jordaan, and B. Mandebvu, "Monitoring droughts in Eswatini: a spatiotemporal variability analysis using the Standard Precipitation Index," Jàmbá: Journal of Disaster Risk Studies, vol. 11, no. 1, pp. 1-11, 2019.

[20] M. Agnoletti, A. Errico, A. Santoro, A. Dani, and F. Preti, "Terraced landscapes and hydrogeological risk. Effects of land abandonment in Cinque Terre (Italy) during severe rainfall events," Sustainability, vol. 11, no. 1, p. 235, 2019.

[21] W. C. Palmer, Meteorological Droughts, Vol. 45, US Department of Commerce, Weather Bureau Research Paper, Washington, DC, USA, 1965.

[22] W. J. Gibbs and J. V. Maher, "Rainfall Deciles as Drought Indicators," bureau of meteorology bulletin, Commonwealth of Australia, vol. 48, no. 29, Melbourne, Australia, 1967.

[23] T. B. McKee, N. J. Doesken, and J. Kleist, "The relationship of drought frequency and duration to time scales," in Proceedings of the 8th Conference on Applied Climatology, vol. 17, no. No. 22, pp. 179-183, American Meteorological Society, Boston, MA, January 1993.

[24] B. Yisehak and A. Zenebe, "Modeling multivariate standardized drought index based on the drought information from precipitation and runoff: a case study of Hare watershed of Southern Ethiopian Rift Valley Basin," Modeling Earth Systems and Environment, vol. 7, no. 2, pp. 1005-1017, 2021.

[25] A. L. Long, "Drought," Disturbance and Sustainability in Forests of the Western United States, p. 992, 2021.

[26] K. R. Dhurmea, R. Boojhawon, and S. D. D. V. Rughooputh, "A drought climatology for Mauritius using the standardized precipitation index," Hydrological Sciences Journal, vol. 64, no. 2, pp. 227-240, 2019.

[27] J. P. Bloomfield and B. P. Marchant, "Analysis of groundwater drought building on the standardised precipitation index approach," Hydrology and Earth System Sciences, vol. 17, no. 12, pp. 4769-4787, 2013.

[28] J. F. Santos, M. M. Portela, M. Naghettini, J. P. Matos, and A. T. Silva, "Precipitation thresholds for drought recognition: a further use of the standardized precipitation index, SPI," River Basin Management VII, vol. 172, 2012.

[29] J. D. Pontes Filho, M. M. Portela, T. Marinho de Carvalho Studart, and F. D. A. Souza Filho, "A continuous drought probability monitoring system, CDPMS, based on copulas," Water, vol. 11, no. 9, 2019.

[30] S. Grimaldi and F. Serinaldi, "Asymmetric copula in multivariate flood frequency analysis," Advances in Water Resources, vol. 29, no. 8, pp. 1155-1167, 2006.

[31] A. K. Nikoloulopoulos, H. Joe, and H. Li, "Vine copulas with asymmetric tail dependence and applications to financial return data," Computational Statistics \& Data Analysis, vol. 56, no. 11, pp. 3659-3673, 2012.

[32] H. Van de Vyver and J. Van den Bergh, "The Gaussian copula model for the joint deficit index for droughts," Journal of Hydrology, vol. 561, pp. 987-999, 2018.

[33] F. Durante, J. Fernández-Sánchez, and C. Sempi, "A topological proof of Sklar's theorem," Applied Mathematics Letters, vol. 26, no. 9, pp. 945-948, 2013.

[34] B. Schweizer, "OPERATIONS ON DISTRIBUTION FUNCTIONS NOT DERIVABLE FROM OPERATIONS ON RANDOM VARIABLES," Studia Mathematica, vol. 52, no. 1, 1974.

[35] R. B. Nelsen, An Introduction to Copulas, Springer Science \& Business Media, Germany, 2007.
[36] X. Li, B. He, X. Quan, Z. Liao, and X. Bai, "Use of the standardized precipitation evapotranspiration index (SPEI) to characterize the drying trend in southwest China from 1982-2012," Remote Sensing, vol. 7, no. 8, Article ID 10917, 2015.

[37] Q. Z. Chaudhry and G. Rasul, "Global warming and expected snowline shift along northern mountains of Pakistan," in Proceedings of the 1st Asiaclic Symposium, Yokohama, Japan, 2007.

[38] N. Faisal and N. Sadiq, "Climatic zonation of Pakistan through precipitation effectiveness index," Pak. J. Meteorol, vol. 6, no. 16, pp. 51-60, 2009.

[39] R. Niaz, I. M. Hussain, Z. Ali et al., "A novel spatially weighted accumulative procedure for regional drought monitoring," Tellus A: Dynamic Meteorology and Oceanography, vol. 72, 2020.

[40] I. Nalbantis and G. Tsakiris, “Assessment of hydrological drought revisited," Water Resources Management, vol. 23, no. 5, pp. 881-897, 2009.

[41] C. T. Agnew, Using the SPI to Identify Drought, 2000.

[42] V. P. Singh and L. Zhang, "IDF curves using the Frank Archimedean copula," Journal of Hydrologic Engineering, vol. 12, no. 6, pp. 651-662, 2007.

[43] X. Zhang and K. A. Hoo, "Effective fault detection and isolation using bond graph-based domain decomposition," Computers \& Chemical Engineering, vol. 35, no. 1, pp. 132$148,2011$.

[44] S. A. Awan, "The climate and flood risk potential of northern areas of Pakistan," Science Vision, vol. 7, no. 3-4, pp. 100-109, 2002.

[45] G. Naheed and A. Mahmood, "Water requirement of wheat crop in Pakistan," Pakistan Journal of Meteorology, vol. 6, no. 11, pp. 89-97, 2009.

[46] N. U. Ain, M. Latif, K. Ullah et al., "Investigation of seasonal droughts and related large-scale atmospheric dynamics over the Potwar Plateau of Pakistan," Theoretical and Applied Climatology, vol. 140, no. 1, pp. 69-89, 2020.

[47] R. Jilani, M. Haq, and A. Naseer, "A study of glaciers in northern Pakistan," in The First Joint PI Symposium of ALOS Data Nodes for ALOS Science Program in Kyoto Secretariat, pp. 19-23, Japan Aerospace Exploration Agency (JAEA), Kyoto International Conference Centre, Main Hall, 2007.

[48] A. B. Farooqi, A. H. Khan, and H. Mir, "Climate change perspective in Pakistan," Pakistan Journal of Meteorology, vol. 2, no. 3, 2005.

[49] M. Abid, J. Schilling, J. Scheffran, and F. Zulfiqar, "Climate change vulnerability, adaptation and risk perceptions at farm level in Punjab, Pakistan," The Science of the Total Environment, vol. 547, pp. 447-460, 2016.

[50] I. Khan, H. Lei, I. A. Shah et al., "Farm households risk perception, attitude and adaptation strategies in dealing with climate change: promise and perils from rural Pakistan," Land Use Policy, vol. 91, Article ID 104395, 2020.

[51] W. Malik, H. Shahid, R. Zafar et al., "Role of Pakistan in global climate change through greenhouse gas emissions (GHGs)," Research Journal of Environmental and Earth Sciences, vol. 4, no. 11, pp. 996-1001, 2012.

[52] F. Tosunoglu and I. Can, "Application of copulas for regional bivariate frequency analysis of meteorological droughts in Turkey," Natural Hazards, vol. 82, no. 3, pp. 1457-1477, 2016.

[53] Z. Ali, I. Hussain, M. Faisal, A. M. Shoukry, S. Gani, and I. Ahmad, "A framework to identify homogeneous drought characterization regions," Theoretical and Applied Climatology, vol. 137, no. 3, pp. 3161-3172, 2019. 